\title{
sciendo
}

\author{
RESEARCH PAPERS FACULTY OF MATERIALS \\ SCIENCE AND TECHNOLOGY IN TRNAVA \\ SLOVAK UNIVERSITY OF TECHNOLOGY \\ IN BRATISLAVA
}

2020, Volume 28, Number 46

DOI 10.2478/rput-2020-0010

\section{DESIGN AND MANUFACTURING OF A TURNING TABLE FOR POLISHING TANKS IN BEER INDUSTRY}

\author{
Catalin BUCIUMAN ${ }^{1}$, Aurelian ADAM $^{1}$, Laurentiu GALATAN $^{1}$ \\ ${ }^{1}$ TeChNicAl University of Cluj-NAPOCA, FACUlTy OF MAChine Building \\ B-DUL MUNCII NO 103-105, CLUJ-NAPOCA, ROMANIA \\ e-mail: Catalin.buciuman08@gmail.com, adamaurelian95@yahoo.ro, \\ galatanlaurentiu23@gmail.com \\ Received 15 April 2020, accepted 29 May 2020, published 25 June 2020
}

\begin{abstract}
The main objective of this paper was to design and manufacture a turning table for fixing conical and tori spherical heads used for tanks in beer industry, to polish the surfaces and to obtain better quality and roughness. The turning table is an indispensable fixture device in the polishing process for vessel heads, where the accuracy and the roughness of the surface is an important factor because it can influence the quality of the beer. If the surface is smooth, the microbes and bacteria cannot be deposited on the tanks' surfaces and also a good quality of the tanks' walls prevent contamination in the beer composition. The research were made in Inotec Company, Romania. The new proposed design for the turning table improved the actual technology and reduced the manufacturing time. The tests made on the obtained manufactured products using the rotary table showed that the surface quality was improved too.
\end{abstract}

Key words

Rotary table, roughness, grinding

\section{INTRODUCTION}

The fixtures devices are economical devices in order to produce a component in a simple way in mass production. These are special work holding and tool guiding devices. Quality of performance of a process is largely influenced by the quality of jigs and fixtures used for this purpose [1]. What makes a fixture unique is that each one is built to fit a particular part or shape. The purpose of a fixture is to locate and to hold a work piece during an operation. A jig differs from a fixture in the sense that if guides the tool to its correct position or towards its correct movement during and operation in addition to locating and supporting the work piece [2].

Polishing and buffing are finishing processes for smoothing a workpiece's surface using an abrasive and a work wheel or a leather strop. Technically polishing refers to processes that use an abrasive that is glued to the work wheel, while buffing uses a loose abrasive applied to the work wheel. Polishing is a more aggressive process while buffing is less harsh, which leads to 
a smoother, brighter finish. A common misconception is that a polished surface has a mirror bright finish, however most mirror bright finishes are actually buffed [3]. Polishing is often used to enhance the appearance of an item, prevent contamination of instruments, remove oxidation, create a reflective surface, or prevent corrosion in pipes. In metallography and metallurgy, polishing is used to create a flat, defect-free surface for examination of a metal's microstructure under a microscope. Silicon-based polishing pads or a diamond solution can be used in the polishing process. Polishing stainless steel can also increase the sanitary benefits of it [4]. The removal of oxidization (tarnish) from metal objects is accomplished using a metal polish or tarnish remover; this is also called polishing. To prevent further unwanted oxidization, polished metal surfaces may be coated with wax, oil, or lacquer. This is of particular concern for copper alloy products such as brass and bronze [5].

The polishing process can be done manually also but is glued to precision and control. Polishers machines are used to obtain a fine (low Ra) surface finish of a part. To improve surface finish, they use abrasive grain slurries or compounds on: buffs, bobs, cloth naps, laps, very fine grit non-wovens, coated abrasives [6].

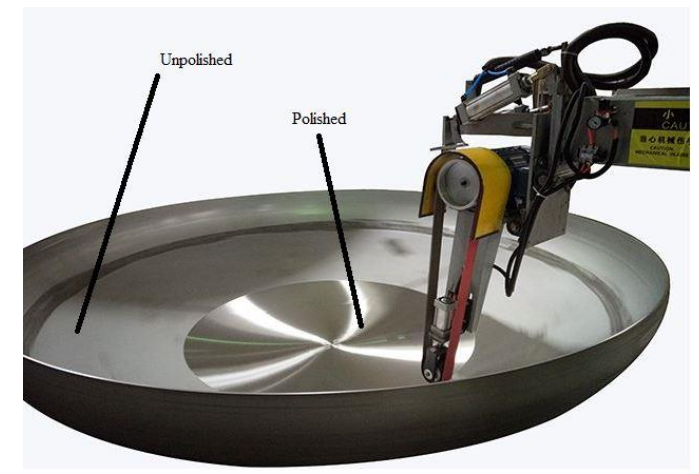

Figure 1 Tank head with an unpolished and a polished surface [4]

In scientific literature there are studies regarding the importance of roughtness in food and beverage industry. Contamination on tank surfaces can be fatal to the product quality due to long processing times with nutritious raw materials, where microbial growth leads to discarding large product batches [7]. Especially the bottom of the tank and discharge arm, the roughness must be smaller, in case the bacteria survived. According with the research made by Tiantai Company [8], the polishing is very important during the manufacturing of beer brewing tanks. They generally adopted acid pickling and passivation which will remove the welding oxygen firstly and then form a protection layer on the tank surface. The accuracy of the tank will reach $0.2-0.4 \mu \mathrm{m}$. Generally the roughness of the welding line must to reach $0.4-0.5 \mu \mathrm{m}$ after polishing.

Chiara De Giorgia and collaborators [9] made a reseach focused on the importance of roughness from the stainless steels surface in food and beverage industry. Within thier research, they used stainless steel 304 alloy sheets, cold rolled to $0.5 \mathrm{~mm}$ thickness. The surface average roughness $R$ a was $85.3 \pm 2.8 \mathrm{~nm}$, instead the surface average waviness Ra was $56.4 \pm 5.6 \mathrm{~nm}$. Before laser micro-polising, they cleaned the specimens in ultrasonic bath cleaning with deionized water (10 minutes), ethanol (10 minutes) and deionized water (10 minutes). Then they dry the samples in nitrogen. They successfully demonstrated that the perfomance of LMP treatment in improvement of the surface finishing, also for an already good initial surface roughness. As was observed with focus variation microscopy, this is due to the filling of surface asperities and grain boundaries with the molten material surface during remelting process [9].

Company Inotec from Cluj-Napoca is manufacturing and assembling process equipment in the food, beverage, pharmaceutical and body maintenance industry. In present, in the company Inotec the polishing process is manually made by a worker with a manual polishing machine 
and the part is fixed on a fix clamping device. The process productivity is very low, the required time for polishing is very large and the worker cannot control it.

Taking into considerations these aspects, it was determined the need of improving the polishing process by designing and manufacturing a rotative table which will rotate the part and the polishing machine can act from all angles.

The old method for polishing has many limitations, like manufacturing time, low accuracy due to many handlings which lead to high manufacturing costs for the parts and inadequate roughness.

The paper is proposing a new concept for the table of the polishing machines, a turning table for polishing which can resolve all the limitations from existing one and will also increase the part surface quality.

\section{MATERIALS AND METHODOLOGY OF EXPERIMENT}

The turning/rotary table is used for fixing and centring the conical and tori spherical vessel heads. For this kind of product the accuracy $0 *$ and roughness is very important. The polishing of the conical and tori spherical vessel heads is important after the rolling process. The rolling process deteriorates the surface of the metallic sheet and a polishing process is mandatory.

For this turning table the number of revolutions per minute can be set depending on the polishing required type. The turning table is connected through a programmable logic controller (PLC) at polishing machine.

The new proposed model was designed and manufactured within the Inotec company. The table contain the following components:

- base plate (part of the body assembly);

- the support plate (part of the body assembly) - has the role for fixing gearmotor and fix part from crown gear;

- the plate support for I profiles -the plate has the role to fixing the I profiles and will be fixed on the rotative part of crown gear;

- the crown gear - this assembly of the crown gear has the role of the connection between the body of the table and the rotating parts;

- the gear shaft has the role to transmit the rotations from gearmotor to the crown gear;

- the I profile on which is installed the linear guide;

- the support plate, part of the head support;

- the shaft has the role to support the rollers;

- the head support on which it is mounted rollers. On this head support will be also welded the block from linear guide;

- the pentagonal part which has the role to sustain the head when it is polished on the interior surface;

- the centring head shaft which has the role to centring and fixing the head.

Following the component parts of the turning table will be presented and details about the steps of the design and technical drawings.

In the figure 2 is presented the $3 \mathrm{D}$ model of the turning table for fixing conical and tori spherical heads. 


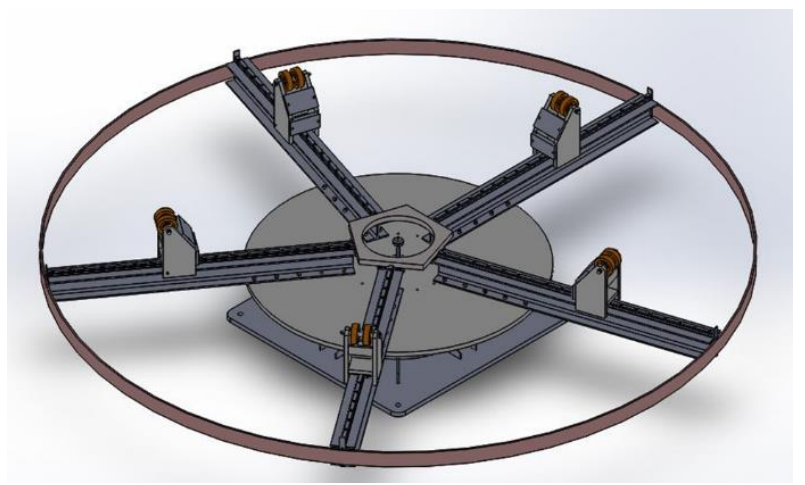

Figure 2 The 3D model of the turning table for fixing conical and tori spherical heads

Figure 3 ilustrates the base plate, part of the body assembly. The base plate is realized from steel S 355 and is manufactured through laser cutting from a sheet metal with thickness $25 \mathrm{~mm}$.

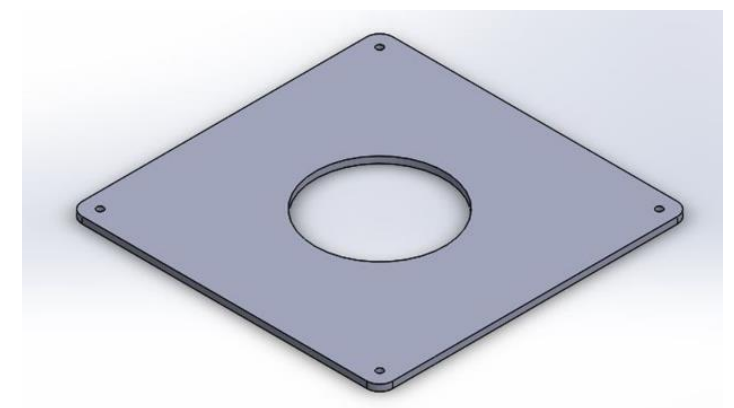

Figure 3 The base plate $3 D$ model

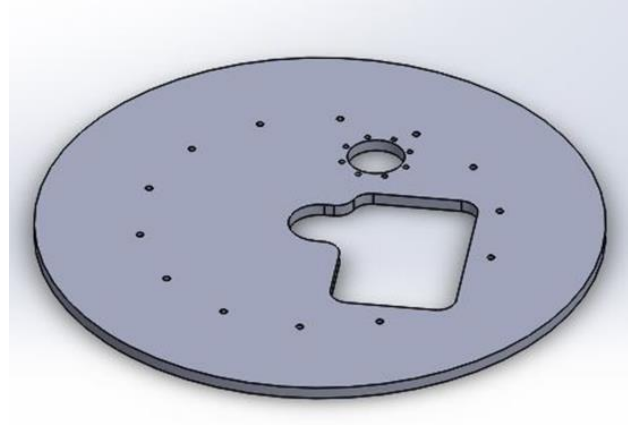

Figure 4 The support plate 3D model

The support plate is part of the body assembly, presented in Figure 4. The support plate has the role for fixing gearmotor and fix part from crown gear. Is realized from steel S 355 and is manufactured through laser cutting from a sheet metal with thickness $25 \mathrm{~mm}$. The holes for fixing gearmotor are clearance holes $\varnothing 9$ and the holes for fixing the fix part from crown gear are tapped M12.

The body assembly is realized through welding of 5 different parts (Figure 5). The shell is realized by cutting a pipe with exterior diameter $\varnothing 762 \mathrm{~mm}$ and thickness $8 \mathrm{~mm}$ at height 200 $\mathrm{mm}$. The ribs have the role of strengthering the body. After welding the body is electrostatic painted, to prevent rust.

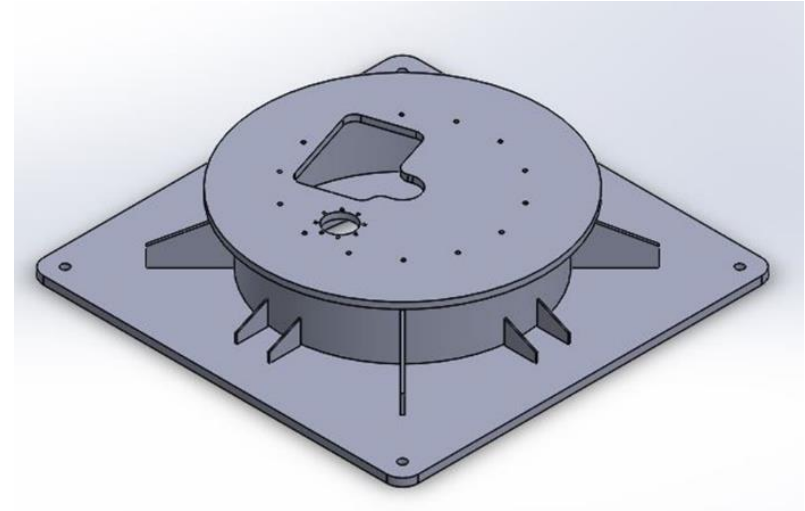

Figure 5 The 3D model of the welded body

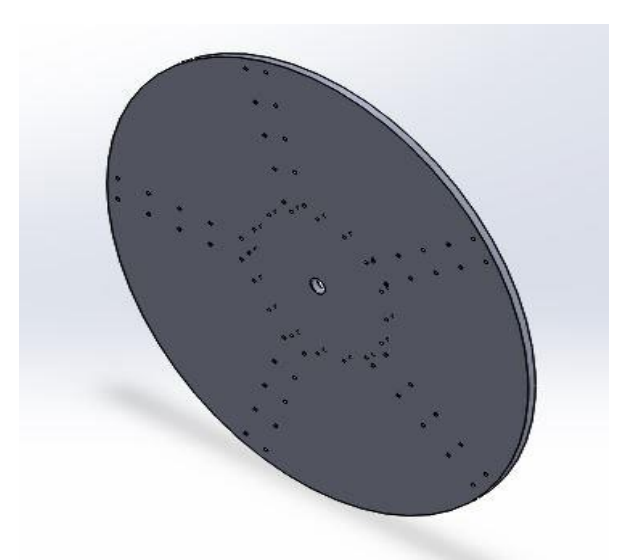

Figure 6 The plate support for I profiles 
In Figure 7 is presented the assembly of the crown gear. This assembly of the crown gear has the role of the connection between the body of the table and the rotating parts. The crown gear is meshing with the gear shaft obtaining the circular motion of the turning table. It has the module 4.5 , number of teeth is 101 , face width is $46 \mathrm{~mm}$ and the outside diameter $\underline{\varnothing} 531$. The gear crown was bought.

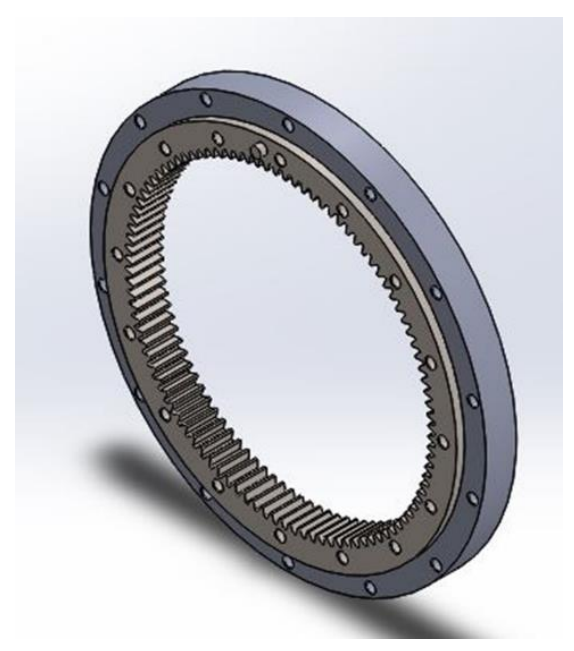

Figure 7 The crown gear 3D model

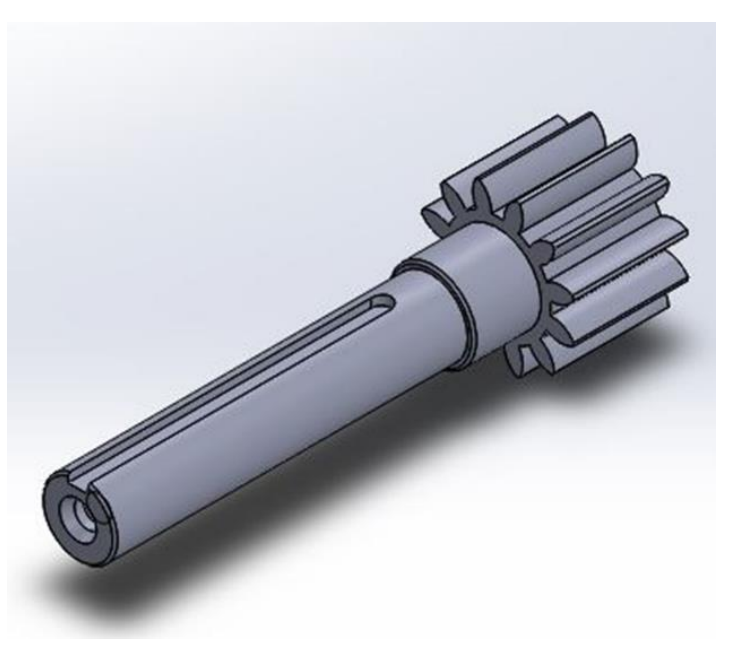

Figure 8 The gear shaft 3D model

The gear shaft presented in figure 8 has the role to trasmit the rotations from gearmotor to the crown gear. The module of the gear shaft is 4.5 , number of teeth is 12 and the face width is $46 \mathrm{~mm}$. The gear shaft is fixed in gearmotor with a screw M10 and with a parallel key. The gear shaft is machined and is hardened and tempering, material of the gear shaft is $1 \mathrm{C} 60$.

In the Figure 9 is presented the I profile on which is installed the linear guide. The I profile is manufactured from steel S 355 . The I profile is electrostatic painted to prevent rust. The upper suface of the part is milling in order to ensure proper mounting of linear guide. The tapped holes are $\mathrm{M} 8$ at a distance of $80 \mathrm{~mm}$.

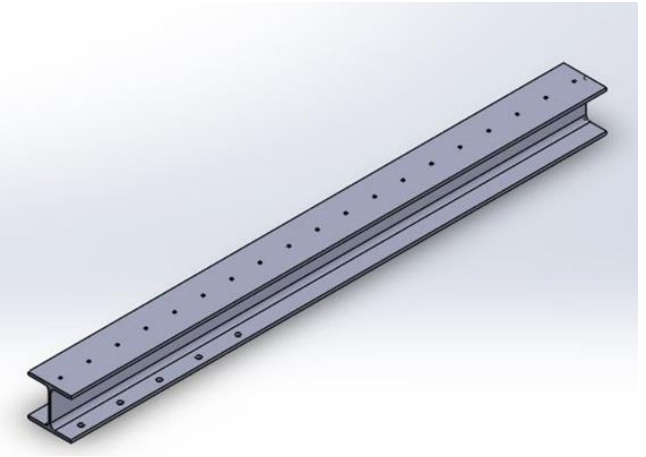

Figure 9 The 3D model of the I profile

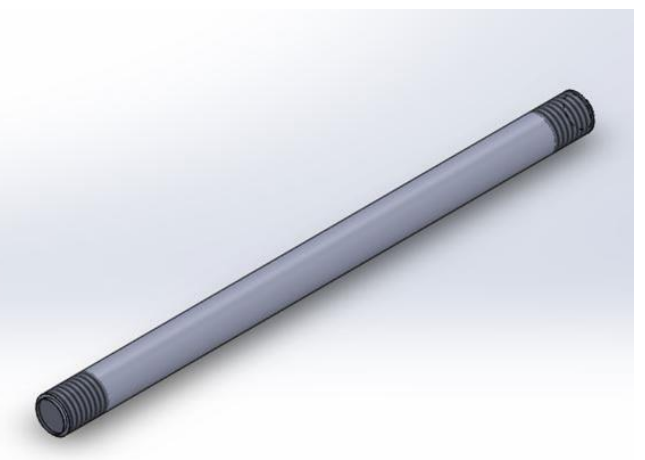

Figure 10 The shaft for fixing rollers

The shaft from Figure 10 has the role to support the rollers, is turned on lathe at the diameter $\underline{\varnothing} 12$ and is tapped M12 at the ends on a length of $15 \mathrm{~mm}$. The material of the shaft is C 45 . 


\section{REACHED RESULTS}

The 3D model of the turning table for polishing the beer tanks was then assembled. The assembled model is presented in Figure 11.

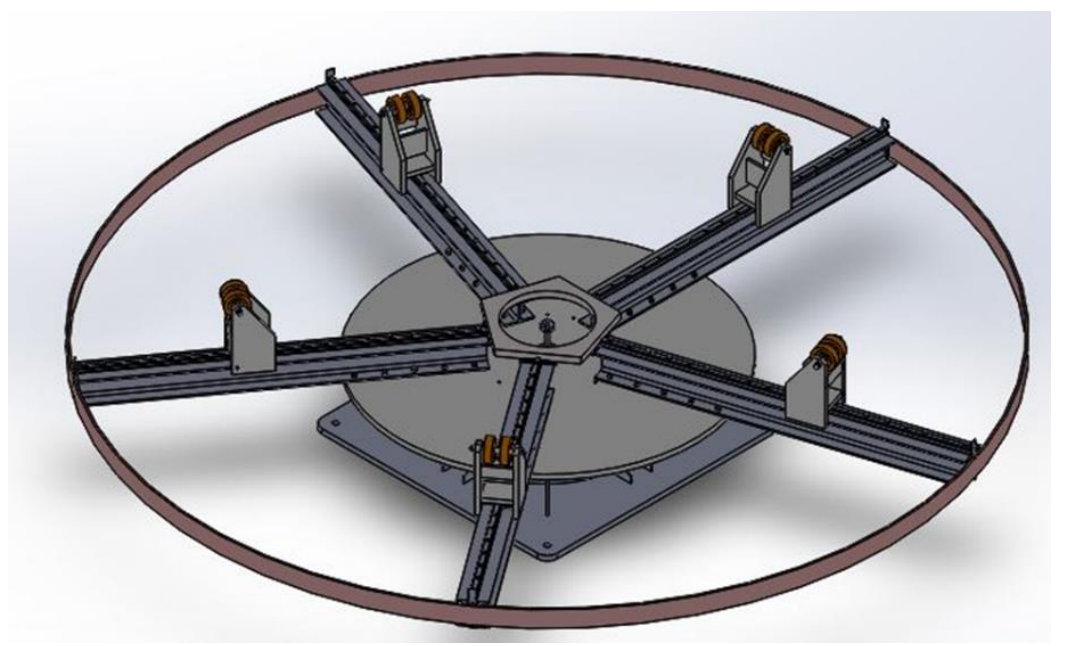

Figure 21 The turning table 3D model in the last step of the assembly process

After all components of the turning table are manufactured the next steps for assembly were required:

In the first step of the assembly process all the parts from body of the turning table were welded.

In the second step in the assembly proccess the gear shaft was assembled in the gearmotor with a key and was fixed with an M10 screw. The gearmotor with the gear shaft was fixed on the body of the turning table with 8 x M8 screws with hexagonal head as shown in Figure 12.

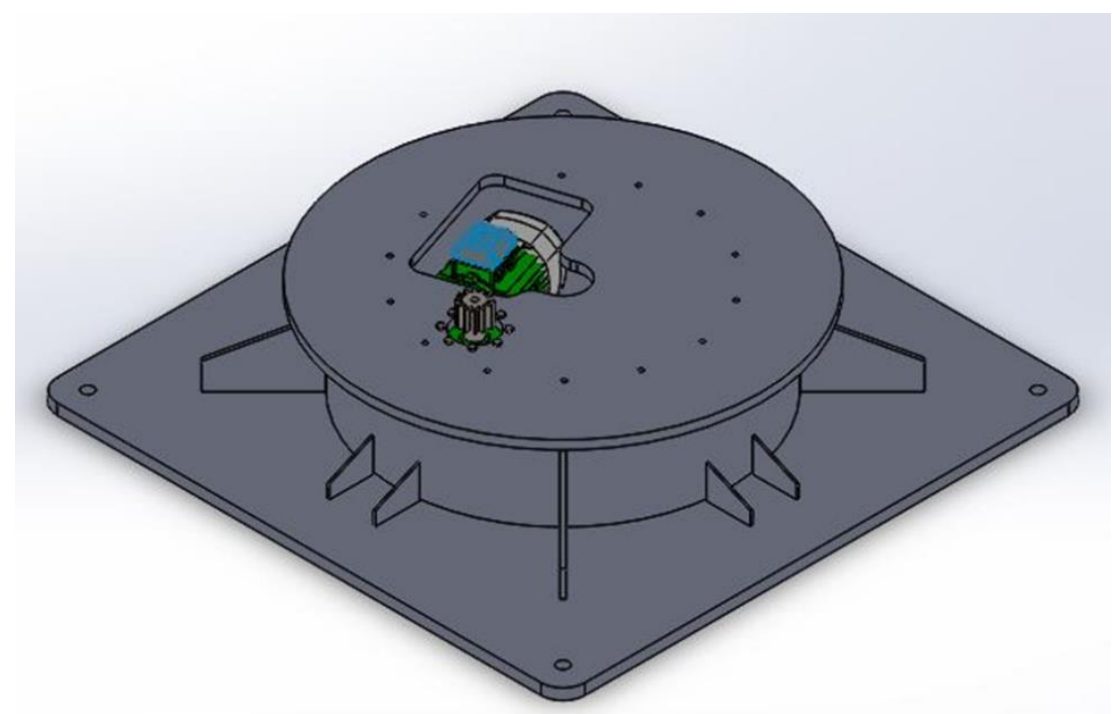

Figure 12 The 3D model of the second step in assembly process

The third step of assembly procces consisted in positioning 14 x M12 screws with hexagonal head on the fix part from the crown gear. After that the rotative part from the crown gear was fixed on the plate support for I profiles with 16 x M12 screws with hexagonal head. 
The fourth step in the assembly process consisted in screwing the screws that were positioned on the fix part from the crown gear on the body of the turning table. A difficulty in this step was to position the screws from the crown gear on the body of the turning table. In the fifth step I profiles were assembled on the plate with M12 screws with hexagonal head. After that the supports for the pentagonal support head were welded on the interior end of the I profiles.

The next step was to assembly the linear guides with M8 socked screws. After that on the holes from linear guides were placed covers to protect from metal powder resulting from polishing process. After the head support was welded and assembled, the rollers and all other parts from head support, these were positionated on the linear guides.

Forwards on the plate support for I profiles was welded a tapped part in which was screwed the centering head shaft. The pentagonal head support was also mounted with $10 \mathrm{x}$ M6 screws with hexagonal head.

The last step consisted in fixing a shell band from stainless steel with M6 socket screws on the I profiles. This band has the role to prevent the accidents at work when the turning table is working.

Most of the parts have been manufactured within the company Inotec, this has led to the reduction of the costs for buying a new equipment. After the manufacturing of all the parts, this turning table has been assembled and connected with a PLC to the polishing machine.

The new table was tested. A conical and tori spherical vessel head of the beer tank were fixed and centred onto the rotary table and it were polished. Were made more tests with different values of rotations for the table in order to check the quality and the roughness values for the polished surfaces, using a Surface Roughness Tester (Stylus Model Elcometer 7061). Inotec.

In Figure 13 is presented a photo with turning table manufactured within the company

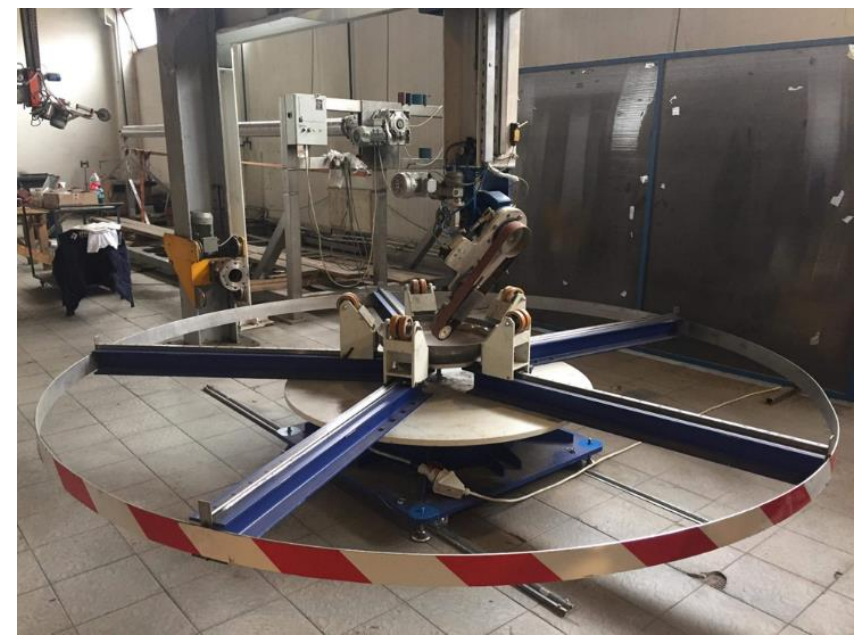

Figure 33 Turning table for fixing conical and torispherical heads

\section{CONCLUSION}

The new proposed designed and manufactured rotary table improved the actual technology used in Inotec company. Changing the manual polishing with a machine, the process become more productive, by reducing the manufacturing time and costs. Manual errors of fixation during the operative time, were also removed.

Most of the parts for rotary table components have been manufactured within the company. This helped to reduce the costs because the externalization of the manufacturing process was 
not needed. Also, the existing infrastructure from the company permitted the manufacturing of the rotary table without buying other special tooling or new equipment.

By using the turning/rotary table to fix the heads of the beer tanks in order to polish with a polishing machine and not manually by a worker, after the roughness tests, the following conclusions were made:

- the control of roughness and quality surfaces were better, which decreased the risk to contaminate the content of the beer tanks'.

- the manufacturing time was reduced, the productivity of the process was increased so, in this way the company have become more competitive in production domain.

\section{References}

[1] ODHIAMBO, 2016. Jigs and Fixtures - Lab Report.

[2] THORAT, S. Introduction and Difference Between Jig And Fixture, Manufacturing Technology, Learn Mechanical Engineering.

[3] http://www.nitc.ac.in/dept/me/jagadeesha/mev303/CHAPT_INTRODUCTION_TO_JIG S_AND\%20FIXTURES.pdf [Accessed: 05-2020]

[4] ADAM, A. 2018. Design and manufacturing of a turning table for fixing conical and torispherical heads, with a view to polishing, used for tanks in beer industry. Bachelor Thesys. Technical University of Cluj-NApoca, Romania.

[5] DECK, C. 2016. Care and Preservation of Historical Brass and Bronze. Benson Ford Research Center,

[6] https://www.globalspec.com/learnmore/manufacturing_process_equipment/abrasives_grinding_fi nishing/grinding_machines_finishing_equipment/polishers_buffing_machines [Accessed: 052020]

[7] SALO S., FRIIS, A., WIRTANEN, G. 2005. Improving the cleaning of tanks, Handbook of Hygiene Control in the Food Industry, Woodhead Publishing Series in Food Science, Technology and Nutrition, 497-506.

[8] http://www.craftbreweryequipment.com/ [Accessed: 05-2020]

[9] DE GIORGIA, C., FURLANA, V., DEMIRA, A., s.a, 2016. Laser micro-polishing of stainless steel for antibacterial surface applications. In: Procedia CIRP, 49, $88-93$. 